\title{
Environmental filtering structures fungal endophyte communities in tree bark
}

\author{
Peter T. Pellitier ${ }^{1}$ (D) | Donald R. Zak ${ }^{1,2}$ | Sydney O. Salley ${ }^{1}$
}

${ }^{1}$ School for Environment and Sustainability, University of Michigan, Ann Arbor, MI, USA

${ }^{2}$ Department of Ecology \& Evolutionary Biology, University of Michigan, Ann Arbor, MI, USA

\section{Correspondence}

Peter T. Pellitier, School for Environment and Sustainability, University of Michigan, Ann Arbor, MI, USA.

Email: ptpell@umich.edu

\begin{abstract}
The factors that control the assembly and composition of endophyte communities across plant hosts remains poorly understood. This is especially true for endophyte communities inhabiting inner tree bark, one of the least studied components of the plant microbiome. Here, we test the hypothesis that bark of different tree species acts as an environmental filter structuring endophyte communities, as well as the alternative hypothesis, that bark acts as a passive reservoir that accumulates a diverse assemblage of spores and latent fungal life stages. We develop a means of extracting high-quality DNA from surface sterilized tree bark to compile the first culture-independent study of inner bark fungal communities. We sampled a total of 120 trees, spanning five dominant overstorey species across multiple sites in a mixed temperate hardwood forest. We find that each of the five tree species harbour unique assemblages of inner bark fungi and that angiosperm and gymnosperm hosts harbour significantly different fungal communities. Chemical components of tree bark $(\mathrm{pH}$, total phenolic content) structure some of the differences detected among fungal communities residing in particular tree species. Inner bark fungal communities were highly diverse (mean of 117-171 operational taxonomic units per tree) and dominated by a range of Ascomycete fungi living asymptomatically as putative endophytes. Together, our evidence supports the hypothesis that tree bark acts as an environmental filter structuring inner bark fungal communities. The role of these potentially ubiquitous and plant-specific fungal communities remains uncertain and merits further study.
\end{abstract}

KEYWORDS

endophytes, environmental filtering, microbial diversity, plant-fungal interactions, tree bark

\section{1 | INTRODUCTION}

Fungal endophytes comprise a critical and ubiquitous component of the plant microbiome, forming cryptic asymptomatic infections in virtually all above- and below-ground plant tissues (Rodriguez, White, Arnold, \& Redman, 2009). Some endophytic fungi may act as mutualists under certain conditions (Christian, Herre, \& Clay, 2019) by producing a wide range of bioactive compounds, including plant hormones and herbivory deterrents (Arnold et al., 2003; Porras-Alfaro
\& Bayman, 2011; Strobel \& Daisy, 2003). Paradoxically, other fungi frequently isolated from asymptomatic plant tissue are placed in taxonomic groups typically associated with saprotrophs or plant pathogens, leading to the suggestion that some fungi recovered living as endophytes also occur as a range of other lifestyles (Carroll, 1988; Lofgren et al., 2018; Selosse, Schneider-Maunoury, \& Martos, 2018).

Endophytic fungi dwelling in inner tree bark have been reported for several decades (Griffith \& Boddy, 1990; Webber, 1981); however, despite significant advances in the study of foliar, root, flower 
and wood endophyte communities, tree bark represents an especially unexplored component of the plant microbiome (Rodriguez et al., 2009; Schulz \& Boyle, 2005; Vandenkoornhuyse, Quaiser, Duhamel, Van, \& Dufresne, 2015). Few studies have attempted to characterize the potentially diverse fungal communities that inhabit inner bark (Griffith \& Boddy, 1990) and the turnover of these communities among plant species and geographical regions is poorly understood (Kowalski \& Kehr, 1992). Instead, culture-based methods have been used to isolate a subsample of inner bark fungi, primarily focusing on ecologically rare, but medicinally important plant hosts (Griffith \& Boddy, 1990; Stierle, Strobel, \& Stierle, 1993; Verma, Gond, Kumar, Kharwar, \& Strobel, 2007; Zhou, Zhu, Liu, Lin, \& Tang, 2010). The paucity of studies to date may be due to the technical challenge of extracting high-quality DNA from tree bark suitable for PCR amplification (Langrell, 2005).

Fungal communities in tree bark may hold underappreciated ecological significance, as they inhabit one of the largest plant surfaces by area (Evert, 2006) and reside in plant tissue that is frequently the site of devastating insect and associated pathogen attack (i.e., western bark beetle, chestnut blight and Dutch elm disease). For example, some endophytic fungi dwelling in bark can protect trees against Dutch elm disease (Webber, 1981), possibly by producing a range of bioactive compounds (Kusari, Hertweck, \& Spiteller, 2012). The structural complexity of tree bark, encompassing the primary phloem, cortex, epidermis and rytiderm (Srivastava, 1964), may host relatively diverse communities and potentially unknown fungal taxa (Kowalski \& Kehr, 1992). A large component of novel diversity within the kingdom Fungi is likely to reside within endophytic communities (Arnold, Maynard, Gilbert, Coley, \& Kursar, 2000; Rodriguez et al., 2009), but no study to date has described the diversity or composition of inner bark fungal communities across tree hosts and geographical locales using culture-independent techniques.

Host species identity and site characteristics are known to play an important role in the structure of some fungal endophyte communities (Arnold et al., 2000; Coleman-Derr et al., 2016; Glynou, Thines, \& Maciá-Vicente, 2018; Hoffman \& Arnold, 2008; U'Ren \& Arnold, 2016; Zimmerman \& Vitousek, 2012). For example, phylogenetically similar plant species can host more similar communities of foliar endophytes (Arnold, Maynard, \& Gilbert, 2001; Arnold et al., 2000); nonetheless, the ubiquity of host specificity for endophytic communities colonizing plant tissues other than foliage is very poorly understood (Rodriguez et al., 2009), thereby limiting our understanding of the general processes that structure the assembly of endophytic communities across plant tissues.

Large inter- and intraspecies variation in the chemical and physical attributes of tree bark (Srivastava, 1964) suggest that tree species and associated bark chemistry may be a controlling factor in community membership (Griffith \& Boddy, 1990; Kowalski $\&$ Kehr, 1992). Bioactive extracts from tree bark, such as tannins, suberins and alkaloids, can vary dramatically across tree species (Alfredsen, Solheim, \& Slimestad, 2008; Srivastava, 1964; Verma et al., 2007). If fungi are metabolically active in inner bark, these compounds could differentially impact community membership, consistent with evidence suggesting environmental filtering (sensu Kraft et al., 2015). Alternatively, tree bark could simply physically entrap airborne spores or other latent fungal life stages (Rodriguez et al., 2009), thereby acting as a passive reservoir for fungi that constitute a range of lifestyles (i.e., ectomycorrhizal fungi, saprotrophs, pathogens). This alternative hypothesis is plausible, given that seasonal expansion and contraction of metabolically inactive bark provides an avenue for fungal spores and other latent life stages to become lodged and entombed within the numerous crevices.

This work explores several fundamental questions concerning the community composition and diversity of inner bark fungi spanning a range of common temperate tree species. Foremost, we seek to determine the identity and diversity of fungi inhabiting these tissues. Additionally, we test the hypothesis that tree bark acts as an environmental filter structuring the community membership of inner bark fungi. Finally, we aim to explore whether chemical variation in tree bark can account for differences in fungal community composition. Support for our hypotheses would include evidence demonstrating that fungal communities are more similar among tree species than geographical sites. We also explore an alternative hypothesis that tree bark functions as a passive and random reservoir for dead or inactive fungal spores and hyphae spanning a range of ecological lifestyles. Support for this alternative hypothesis could include site-specific structuring of fungal communities with minimal differences among tree species within a site. Additional support for our alternative hypothesis would include findings that chemical attributes of bark are not meaningfully correlated with fungal community composition, thereby suggesting that inner bark fungal communities are random assemblages of latent fungal life stages relatively unaffected by bark chemistry. To accomplish our objectives, we develop a novel and high-throughput means of extracting high-quality fungal DNA to compile the first culture-free survey of fungi inhabiting surface-sterilized tree bark.

\section{2 | METHODS}

\subsection{Field collection of bark tissue}

Three sites were identified in Manistee National Forest, Michigan, USA, and sampled in May 2016. All sites were dominated by plant communities characteristic of mixed temperate hardwood forests (Zak, Host, \& Pregitzer, 1989). Two of the sites were geographically proximal $(<2 \mathrm{~km})$, whereas the third site was more than $8 \mathrm{~km}$ from the other two sites (Figure S1). At each of the three sites, we collected inner bark from the following tree species: black oak (Quercus velutina), white oak (Quercus alba), red pine (Pinus resinosa), eastern white pine (Pinus strobus) and red maple (Acer rubrum). Sampled trees were uniformly distributed as mixed natural assemblages and all 40 trees sampled in each site were found within $150 \mathrm{~m}^{2}$. Diameter at breast height $(\mathrm{DBH})$ for oak and pine species ranged from $\sim 0.5$ to $1.8 \mathrm{~m}$. Individuals of red maple were on average smaller and their $\mathrm{DBH}$ ranged from 0.2 to $0.6 \mathrm{~m}$. These species span a wide range 
of phylogenetic breadth and encompass multiple bark morphologies (Plate S1).

Within each of the three sites, eight individual trees from each of the five species were sampled $(n=120)$. Bark samples were taken at $\mathrm{DBH}$, and an $\sim 10-\mathrm{cm}^{2}$ sample on the geographical north and south side of each tree was aseptically removed to the depth of the vascular cambium using a sharp, sterilized knife (Plate S1). Samples collected on either side of each tree stem were composited and immediately deposited into a sterile Whirl Pack Bag and placed on ice. Only free-standing trees with healthy foliage and visually asymptomatic bark were sampled. Absolute depth of bark sample varied depending on tree species. Bark was stored at $-80^{\circ} \mathrm{C}$ in the lab, until it was processed for DNA extraction.

\section{2 | DNA extraction}

Prior to extraction, samples were surface sterilized to remove epiphytic microorganisms using a standard procedure previously employed for tree bark (Petrini \& Fisher, 1990; Kowalski \& Kehr, 1992; Verma et al., 2007), as well as other plant tissues (Arnold, 2007; Zimmerman \& Vitousek, 2012). No attempt was made to manually remove lichenized fungi, as doing so would damage the sample. The surface sterilizing protocol included submerging the bark sample in $95 \%$ ethanol for $5 \mathrm{~s}, 0.5 \%$ sodium hypochlorite for $2 \mathrm{~min}, 70 \%$ ethanol for $2 \mathrm{~min}$, rinsing by submerging the sample in sterile deionized water for $2 \mathrm{~min}$, and finally an additional minute in fresh sterile deionized water.

The following protocol was found to maximize both DNA quality and yield. To mechanically homogenize samples, a $6.35-\mathrm{mm}$ flame-sterilized drill bit was used to excavate surface-sterilized bark samples perpendicular to the naturally exposed surface. Shavings were collected, pooled and then ground in a sterilized mortar for $30 \mathrm{~s}$ in liquid nitrogen. Pooled bark shavings from each tree were extracted in triplicate; each extraction required $0.1 \mathrm{~g}$ of bark shavings weighed into screw top tubes with three 2-mm stainless steel beads. DNA extraction followed a modified version of the MO-BIO DNeasy Plant Mini Kit protocol. Differences from the manufacturer's protocol include the described upstream mechanical lysis, as well as modifications described below. Chemical lysis of the samples was achieved using the Qiagen Powerlyzer at 394g. for $60 \mathrm{~s}$ with lysis buffer solution and RNase A. Instead of an additional $500 \mu \mathrm{l}$ of Buffer AW2, $500 \mu \mathrm{l}$ of $95 \%$ ethanol was added to the spin column and samples were allowed to incubate for 5 in prior to centrifugation for $2 \mathrm{~min}$ at 16,100 g. The flow-through was discarded, and the spin column was returned to the original tube and centrifuged again for one additional minute at $16,100 \mathrm{~g}$ before transferring to a new $1.5-\mathrm{ml}$ microcentrifuge tube. After qualitative assessment of DNA using gel electrophoresis, DNA was stored at $-20^{\circ} \mathrm{C}$. Assessment of DNA quality was conducted using a Nanodrop Spectrophotometer (Thermo Fisher) and then purified with a MO-BIO PowerClean Kit using the manufacturer's protocol, with minor alterations to prevent ethanol contamination and to concentrate the three extraction replicates. DNA quality was again re-assessed as described above.
The Quant-iT PicoGreen dsDNA Assay Kit (LifeTechnologies) and a BioTek SynergyHT Multi-Detection Microplate Reader (BioTek Instruments) were used to quantify DNA concentrations prior to $\mathrm{PCR}$ (polymerase chain reaction) (median $=7.2 \mathrm{ng} / \mu \mathrm{l}, \mathrm{SD}=7.34 \mathrm{ng} /$ $\mu \mathrm{l})$.

\section{3 | PCR}

The ITS2 region was amplified using Illumina dual-indexed primers 5.8S Fun and ITS4 Fun (Taylor et al., 2016). The forward and reverse primer each contained the appropriate Illumina Nextera adaptor, linker sequence and error correcting Golay barcode for use with the Illumina MiSeq platform. All PCRs were performed in triplicate following Taylor et al. (2016), using Phusion High Fidelity DNA Polymerase and master mix (New England BioLabs). Samples with high concentrations of DNA were diluted for a target template concentration of $0.78-16.5 \mathrm{ng} / \mu \mathrm{l}$ (mean $=8.8 \mathrm{ng} / \mu \mathrm{l})$. Each PCR contained $6 \mu \mathrm{l}$ High Fidelity Phusion $5 \times$ buffer, $0.75 \mu$ leach primer (10 $\mu \mathrm{m}$ initial concentration), $0.42 \mu \mathrm{l}$ dNTPs (20 mm initial concentration of each dNTP), $1.5 \mu$ l of template DNA and $0.23 \mu \mathrm{l}$ of Taq $(2 \mathrm{U} / \mu \mathrm{l})$ brought to a final volume of $20 \mu \mathrm{l}$ with molecular-grade water. PCR conditions consisted of an initial denaturation step at $94^{\circ} \mathrm{C}$ for $3 \mathrm{~min}$, followed by 27 cycles of the following: $30 \mathrm{~s}$ at $94^{\circ} \mathrm{C}$, $45 \mathrm{~s}$ at $57^{\circ} \mathrm{C}$ and $90 \mathrm{~s}$ at $72^{\circ} \mathrm{C}$ followed by a final extension step of $72^{\circ} \mathrm{C}$ for $10 \mathrm{~min}$. PCR amplification was successful for $118 / 120$ of all tree samples. Replicate PCR products were pooled and equimolar concentrations of DNA were sequenced at The University of Michigan, Microbial Systems Molecular Biology Laboratory using a full run of Illumina MiSeq $(2 \times 250 \mathrm{bp}$ ); PhiX oligonucleotides were spiked for base diversity.

\section{4 | Bioinformatic analyses}

All sequence processing was performed using QIIME 1.9.1. A total of $18,051,236$ raw reads were demultiplexed and assigned to unique samples. Reads were then joined using the multiple_join_paired_ends. py script using a conservative 100-bp requirement of sequence overlap (settings -j 100, - p 25). Reads that were unable to be joined were discarded, while joined reads were then subjected to strict quality filtering (-q 19 -p 0.75 -r 3; sensu Taylor et al., 2016). Sequences that were not assigned to Fungi or samples with fewer than 1,000 sequences were removed, resulting in one red pine sample being discarded from our analyses. Average joined read length was $321 \mathrm{bp}$, with a total of 4,442,861 sequences. Reads were clustered to operational taxonomic units (OTUs), using the reference-based USEARCH (version 6; Edgar, 2013) algorithm with 97\% sequence similarity; chimera detection was also performed simultaneously with referencebased detection. Taxonomic identity was assigned using the top BLAST match with the assign_taxonomy.py function in QIIME, using the UNITE fungal reference set (Kõljalg et al., 2013). After processing, there was a median of $3.617 \times 10^{5}$ sequences per sample $\left(S D=1.476 \times 10^{4}\right)$. Rarefying was conducted using the single_rarefaction.py command, with 3,900 sequences (Figures S2 and S3). OTUs that appeared less 
than twice across all samples were removed, and the resulting BIOM file was used for all subsequent statistical analyses (McDonald et al., 2012). Twenty-five OTUs comprised $61 \%$ of unknown sequences and these OTUs were manually assigned using BLAST; manually assigned OTUs were not amended to the data set as identified taxa (Table S4).

\subsection{Chemical characteristics of bark}

Chemical characteristics were measured on bark samples that were not subjected to surface sterilization. Samples were ground and homogenized using a grinder (Krups). Carbon and nitrogen concentrations were determined on a subset of ground samples using a LECO TrueMac $\mathrm{CN}$-analyser. Bark $\mathrm{pH}$ was measured by mixing $1 \mathrm{~g}$ of ground material with $100 \mathrm{ml}$ of deionized water; after $1 \mathrm{hr}$, samples were filtered, and $\mathrm{pH}$ was measured with a glass electrode. Finally, total phenolic content (TPC) of the bark was determined using a procedure described by Ainsworth and Gillespie (2007). The assay employs the Folin-Ciocalteu reagent, which transforms in colour upon accepting electrons from phenolic moieties, making it a general measure of TPC and other oxidizing substrates. Briefly, $22.5 \pm 2 \mathrm{mg}$ of ground bark sample was extracted in $80 \%(\mathrm{v} / \mathrm{v})$ methanol by vortexing at maximum power for $20 \mathrm{~min}$. Samples were then combined with Folin-Ciocalteu reagent and alkalized with $10 \%$ filtered sodium carbonate solution. Samples were analysed in technical triplicates using a microplate reader at $765 \mathrm{~nm}$ (Bio-Tek) with tannic acid as a standard (Ainsworth \& Gillespie, 2007).

\section{6 | Statistical analysis}

Diversity measures (Chao1, inverse simpson) were calculated and compared using two-way ANOVA (analysis of variance), with site $(n=3)$ and tree species $(n=5)$ as fixed factors. Bray-Curtis dissimilarity matrices were generated and principal coordinate analysis ( $\mathrm{PCo} A$ ) plots were used to visualize differences in community composition. To exclusively study fungi inhabiting inner bark, lichenized genera were removed by culling OTU that matched to a database of lichenized fungal genera (Lücking et al., 2017). We then tested for differences in fungal community composition between samples using site and tree species as factors using permutational analysis of variance (PERMANOVA) with Bray-Curtis distance matrices; this analysis calculates a test statistic by comparing dissimilarities between inter- and intraclass objects (Paliy \& Shankar, 2016), implemented using VEGAN version 2.5-4 (Oksanen et al., 2011). To test if centroid location drove significant differences among sites and species, a multivariate test of homogeneity of group differences was conducted using the BETADISPER command in VEGAN, followed by Tukey's honest significant difference (HSD) test of pairwise differences between group means. These analyses were repeated after collapsing OTUs into fungal orders and when OTUs that could not be assigned at the level of fungal order were removed from the data set. Differences between fungal communities inhabiting angiosperm and gymnosperm hosts were also compared using PERMANOVA and BETADISPER tests as above. Average linkage hierarchical clustering, using unweighted arithmetic average clustering (UPGMA) was conducted using the hclust command after computing Bray-Curtis matrices to further visualize differences (Legendre \& Legendre, 2012).

Canonical correspondence analysis (CCA) was used to visualize the variation (inertia) explained by the chemical attributes of the bark substrate (e.g., pH, TPC, N), using Hellinger-transformed species abundance matrices at both the OTU and the order level (Legendre \& Gallagher, 2001). To further test how the chemical characteristics of bark affected the composition of the fungal community, we fitted generalized linear models (GLMs) with the "manyglm" function in MVABUND version 4.0.1 (Wang, Naumann, Wright, \& Warton, 2012) and performed multivariate analyses of deviance with Hellinger-transformed OTU abundances (i.e. ANOVA for models with non-normal error distributions; Warton, Foster, De'ath, Stoklosa, \& Dunstan, 2015). GLMs explicitly model the mean-variance relationship of ecological counts, assuming a negative binomial distribution (Warton et al., 2015), and can be used to reveal the strength and significance of the relationship between a predictor and the response variable (Paliy \& Shankar, 2016). This analysis was carried out after removing lichenized OTUs and we also performed this test on all fungal orders comprising more than $1 \%$ of all sequences. All chemical parameters $(\mathrm{pH}, \mathrm{N}, \mathrm{TPC})$ were included in the model without interaction components (Cuellar-Gempeler \& Leibold, 2019). The effect of predictor variables was quantified using likelihood-ratio tests (ANOVA, pit trap resampling, 999 bootstraps) and Bonferroni correction. We emphasize that the CCA serves as a visualization of the statistically corroborated GLM results (Bálint et al., 2015). Differences in the chemical attributes of trees were compared using two-way ANOVA, with site and species as main effects. Finally, observed fungal diversity was regressed against the chemical attributes of the bark $(\mathrm{N}$, TPC and $\mathrm{pH}$ ) and fit with linear or polynomial models. All analyses were conducted in $\mathrm{R}$ version 3.5.3 (R Core Team, 2019).

\section{3 | RESULTS}

\section{1 | Sequencing yield}

Sequence-based rarefaction curves were nearly asymptotic for most individual samples (Figure S2) and tree species (Figure S3), implying that sequencing depth was largely adequate to capture the diversity of fungi encountered in our samples. In total, 1,945 fungal OTUs were identified in the rarefied data set (clustered at $97 \%$ similarity).

\section{2 | Variation among tree species in inner bark fungal communities}

Tree species was a highly significant factor structuring the composition of inner bark fungal communities (lichenized fungi removed; PERMANOVA: Tree species: $F_{4,116}=17.40, p=.0001, R^{2}=.37$; Figure 1). Multivariate homogeneity of group dispersion of tree species effects was not significant (ANOVA: $F_{4,116}=0.94, p=.4$ ), indicating that differences in fungal community dispersion among groups 


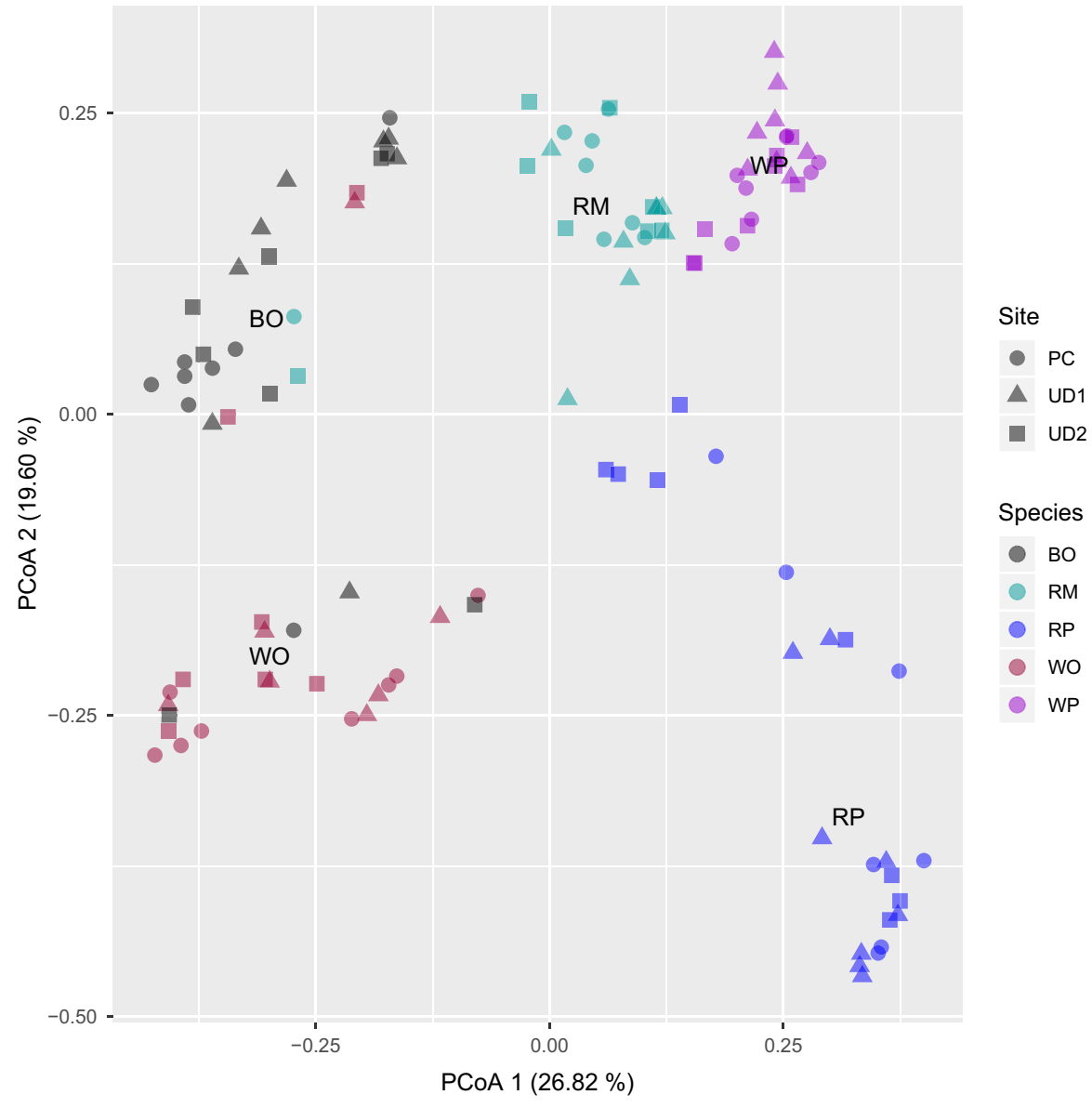

FIGURE 1 Principle coordinates analysis ( $\mathrm{PCoA}$ ) based on Bray-Curtis distance matrices. Fungal OTUs exclude lichenized fungi. Individual points represent inner bark fungal communities from individual trees (colours) and sites (shapes). Plotted tree species labels represent centroid locations. Differences among tree species explain $\sim 20$ times more variation in fungal community composition than does site. BO, black oak; $\mathrm{RM}$, red maple; RP, red pine; WO, white oak; WP, white pine (tree species) was not driving the observed effect of tree species on fungal community composition. Site was also a significant predictor of fungal community composition $\left(F_{2,116}=1.64, p=.018, R^{2}=.032\right)$, and there was a significant site by species interaction on fungal community composition $\left(F_{8,116}=1.38, p=.01\right)$. Interestingly, sites that were geographically closest to one another did not generally have more similar fungal communities (Figure S4). Finally, in accordance with the clustering analysis, there were significant differences between groups, when trees were grouped as angiosperms or gymnosperms and lichenized OTUs were removed $\left(F_{1,116}=3.23, p=.0003\right)$.

Tree species remained a highly significant factor when fungi were grouped at the level of order, and orders dominated by lichenized fungi were removed (PERMANOVA: $F_{4,116}=24.68, p=.0001$, $R^{2}=.47$ ). We could not, however, confirm that this was not driven by greater within-group (tree species) dispersion of fungal community composition (ANOVA: $F_{4,116}=7.93, p=.00001$ ). Moreover, for fungal orders, no significant differences in fungal community similarity among sites was detected $(p=.074)$. Finally, when OTUs that could not be identified at the level of order were removed, we found qualitatively similar results as for the full data set (lichenized fungi removed): Tree species: $F_{4,116}=16.13, p=.0001$, Site: $F_{2,116}=1.48$, $p=.045 ;$ Site $\times$ Species: $F_{8,116}=1.32, p=.0169$.

The chemical characteristics of tree bark varied significantly among tree species (ANOVA: all $p<.001$ ); neither site nor a site by species interaction occurred in our analysis, indicating that bark chemical characteristics were species-specific (Figures S7-S9). Finally, GLMs revealed a significant effect of both $\mathrm{pH}$ and TPC on fungal community composition $(\mathrm{pH}$ : deviance $=388.9, p=.001$; TPC: deviance $=331.8 ; p=.001)$, but not $\mathrm{N}$ content $(p>.5)$. The relative significance of these predictor variables also varied among abundant fungal orders (Table S5; Figure 2).

\section{3 | Fungal diversity}

White pine hosted the most diverse assemblages of inner bark fungi (mean = 171 OTUs, SE = 6.4), whereas red pine (mean = 117 OTUs, $S E=12.4$ ) was the least diverse (Table 1). Two-way ANOVA revealed highly significant differences among plant species in fungal $\alpha$-diversity for both inverse Simpson $(p=.0001)$ and Chao1 measures ( $p=.0001$; Table 1). These results were robust across sampling locations, as no significant differences in tree level $\alpha$-diversity was observed among sites $(p>.5)$.

Fungal communities were heavily dominated by the Ascomycota, which comprised $75 \%$ of all OTUs. At the Class level, Dothideomycetes and Eurotiomycetes were present across all tree species comprising between $10 \%$ and $27 \%$ of all OTUs. A total of 97 fungal orders were detected across all tree species, and the distribution of these orders varied among tree species (Figure 3, 
TABLE 1 Inner bark fungal diversity measures for the studied tree species with lichenized fungi removed
FIGURE 2 Canonical correspondence analysis (CCA) depicting differences among inner bark fungal communities across five tree species. Points represent fungal communities sampled from individual trees, with Hellingertransformed OTU counts. Ordination is constrained by chemical parameters $\mathrm{pH}$, $\mathrm{N}$ content and total phenolic content [TPC]) which together explain $11.8 \%$ of the overall variance (inertia). Plotted fungal order names are scaled centroid coordinates for weighted distances comprising more than $1 \%$ of all OTUs. Axis percentages depict constrained variation. The proximity between labels for plant species and fungal orders can be understood as the probability of occurrence in the bark of a given tree species. BO, black oak; RM, red maple; RP, red pine; WO, white oak; WP, white pine

\begin{tabular}{llrll} 
Tree species & Observed OTUs & \multicolumn{1}{c}{ SE } & Chao1 & Inverse simpson \\
\hline White oak & $122.27^{\mathrm{b}}$ & 8.97 & $178.19^{\mathrm{b}}$ & $11.80^{\mathrm{a}, \mathrm{b}}$ \\
\hline Black oak & $169.42^{\mathrm{b}}$ & 7.13 & $239.26^{\mathrm{a}}$ & $16.16^{\mathrm{c}, \mathrm{e}}$ \\
\hline Red maple & $146.00^{\mathrm{a}}$ & 5.72 & $221.03^{\mathrm{a}}$ & $9.91^{\mathrm{b}}$ \\
\hline Red pine & $113.70^{\mathrm{b}}$ & 12.39 & $182.93^{\mathrm{b}}$ & $4.35^{\mathrm{d}}$ \\
\hline White pine & $171.13^{\mathrm{a}}$ & 6.37 & $261.82^{\mathrm{a}}$ & $15.10^{\mathrm{a}, \mathrm{e}}$ \\
\hline
\end{tabular}

Note: Superscripts denote significant differences at $p<.05$

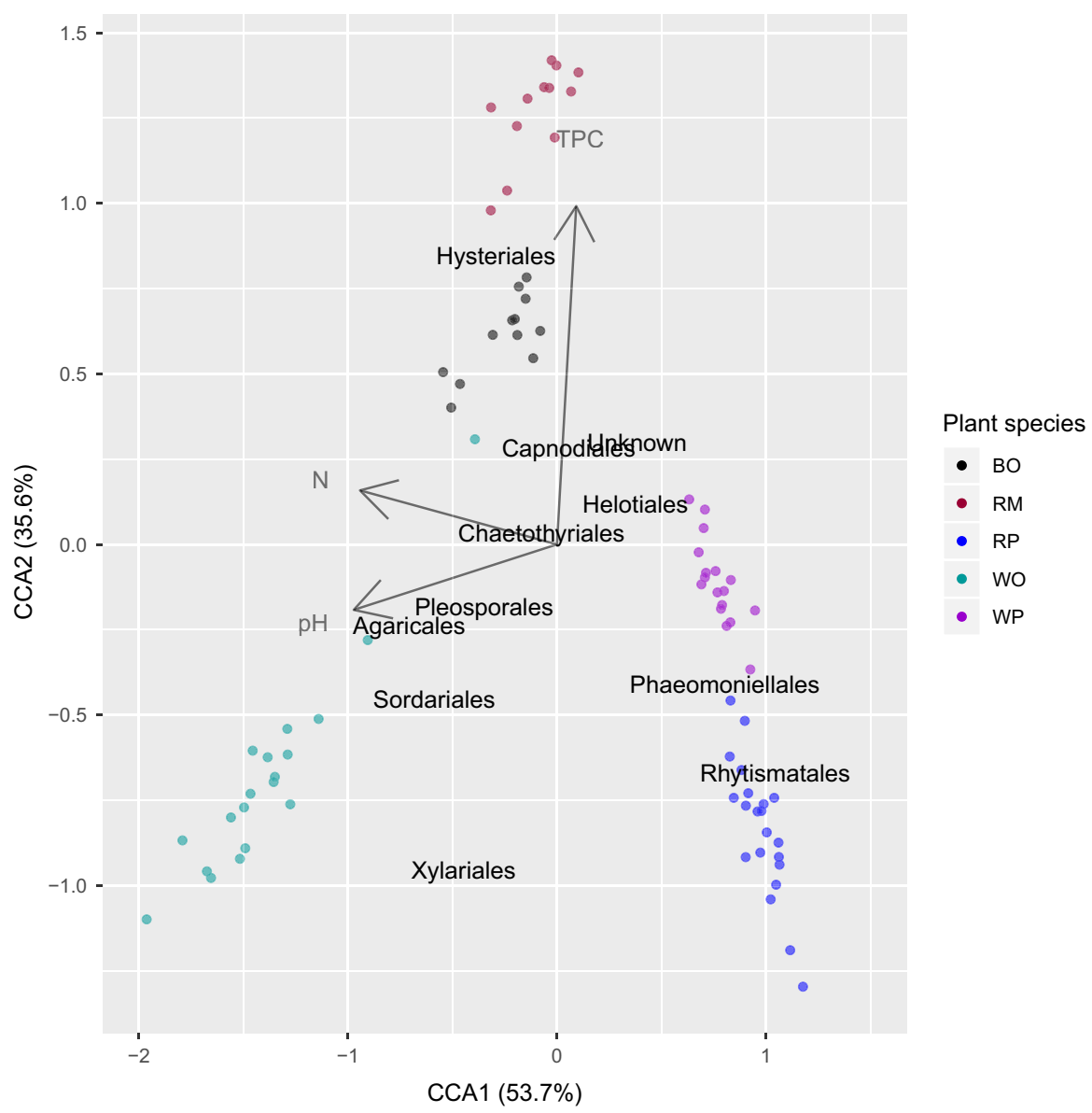

Table S1). More than $41 \%$ of all fungal OTUs detected in red pine belonged to the order Rhytismatales, but this order was nearly absent in all other tree species (Figure 3). Other fungal orders such as the Helotiales were present across all tree species (Table S1). The 25 most abundant unidentified OTUs comprised $61 \%$ of all unidentified sequences (Table S4). Although no attempt was made to mechanically remove lichenized tissue prior to DNA extraction, lichenized OTUs made up a relatively small proportion of our data set, comprising $18 \%$ of all genera observed and only $7 \%$ of all rarefied sequences.

A second-order polynomial fit revealed a significant correlation between TPC and fungal richness ( $p=.001$, adjusted $R^{2}=.17$ ) revealing highest fungal richness at intermediate TPC values (Figure S6). Although significant, $\mathrm{pH}$ accounted for a small proportion of the variance in fungal richness, with diversity peaking in the range of $\mathrm{pH}$ $4-5\left(p=.053, R^{2}=.051\right.$; Figure $\left.\mathrm{S} 6\right)$.

\section{DISCUSSION}

Several lines of evidence support the hypothesis that tree species acts as a strong environmental filter structuring inner bark fungal communities and that these diverse communities are dominated by metabolically active endophytic fungi in asymptomatic surfacesterilized plant tissue (Hardoim et al., 2015). Tree species accounted for $37 \%-47 \%$ of the total variation among fungal communities, depending upon the taxonomic level of fungal communities examined, whereas sampling site location explained only $1.8 \%$ of the total 


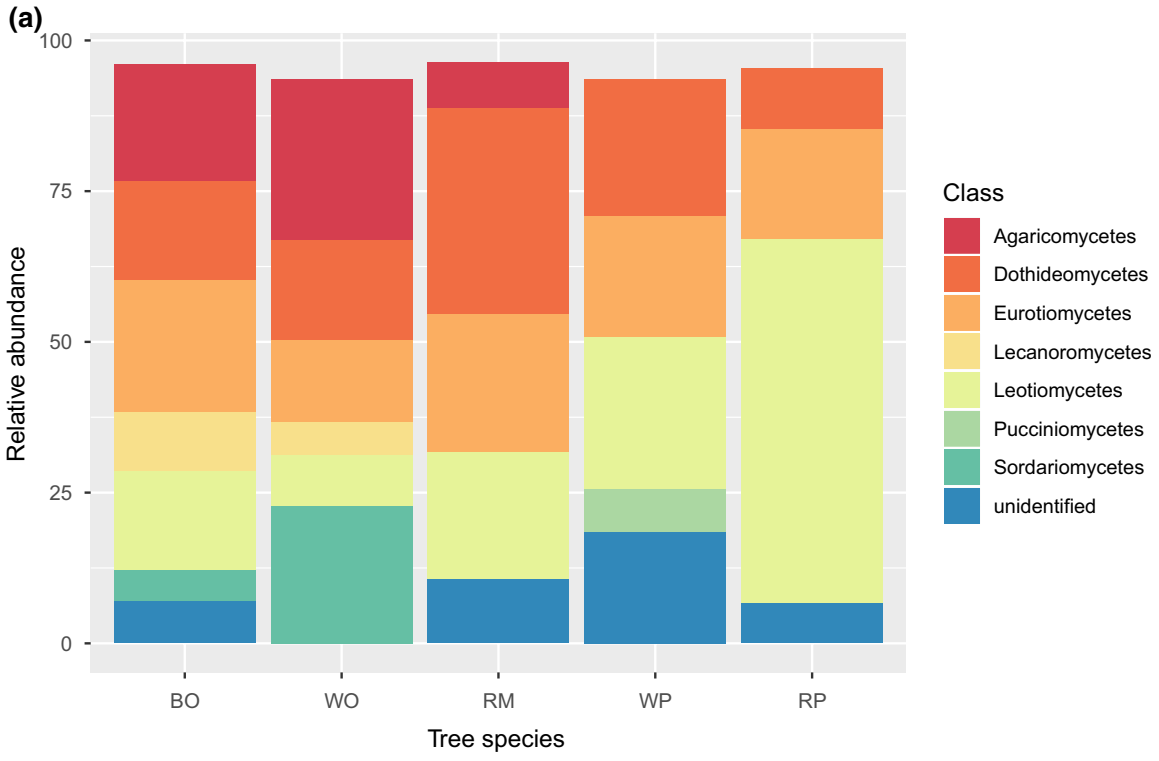

(b)

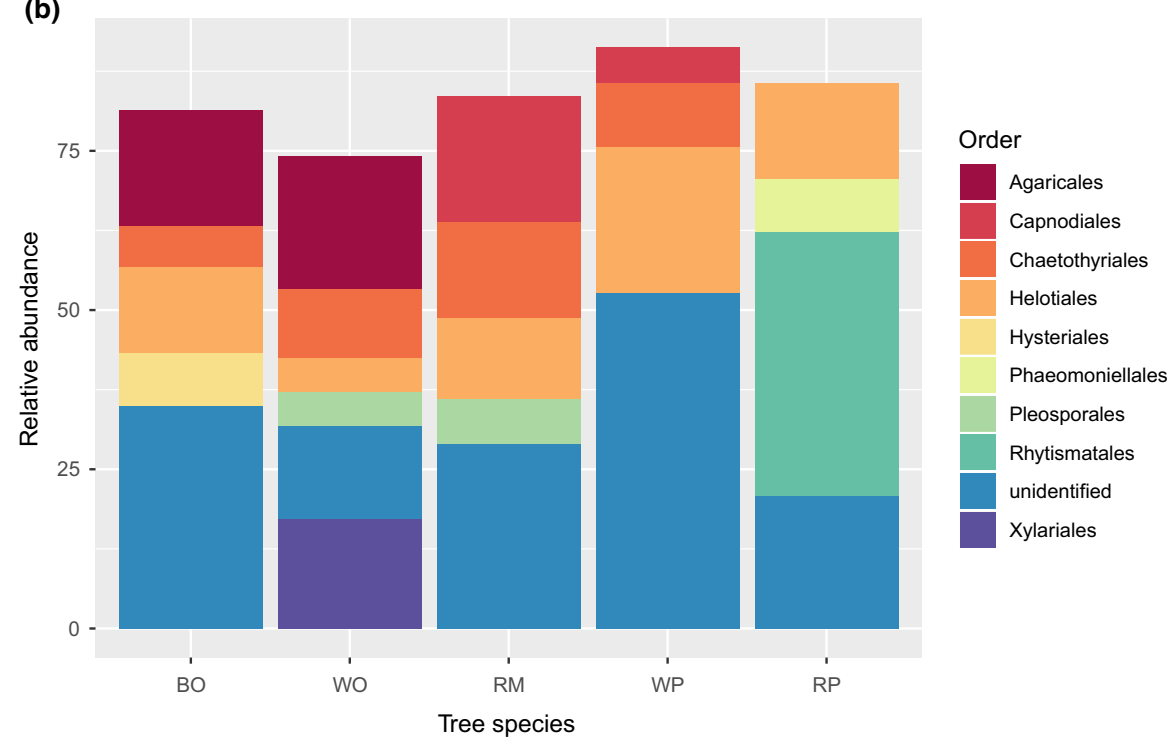

FIGURE 3 Taxonomic composition of fungal (a) classes and (b) orders. Data presented exclude lichenized fungi. Relative abundance is calculated as the average proportion of DNA sequences found within each tree species assigned to each order, comprising more than $5 \%$ of all sequences variation in community composition. These results suggest that inner bark communities are not random assemblages of fungi subject to site-level differences in spore dispersal. Instead, heterogeneity in the bark of different tree species acts as an environmental filter structuring distinct endophytic communities.

Our results are consistent with previous culture-based studies that compared the identify and frequency of inner bark fungi isolated from different tree species (Griffith \& Boddy, 1990; Kowalski \& Kehr, 1992). Griffith and Boddy (1990) found a very high incidence of endophytic infection, and Kowalski and Kehr (1992) found that many fungal taxa could only be isolated from specific tree species. These authors suggested that some endophytic fungi may have strong host specificity, particularly between angiosperm and gymnosperm hosts (Kowalski \& Kehr, 1992). We extend these results by sampling a much larger proportion of the total fungal community encountered within inner bark across a range of common tree species, showing that angiosperm and gymnosperm trees possess significantly different fungal communities. Moreover, we also demonstrate that differences in fungal community structure across tree hosts are maintained at deeper phylogenetic levels (i.e., when fungal communities are grouped at the level of order). Together, our results are broadly congruent with evidence documenting strong turnover of foliar and root endophytic fungal communities across plant hosts (Arnold et al., 2000; Higgins et al., 2007; Hoffman \& Arnold, 2008). As the first such study of its kind, additional sampling across a broader environmental gradient and geographical extent may also reveal sampling sites (and climatic differences) as relatively strong drivers of inner bark fungal community composition (Hoffman \& Arnold, 2008; Webber, 1981; Zimmerman \& Vitousek, 2012).

Both $\mathrm{pH}$ and TPC were significant predictors of fungal community composition, and were also significant predictors for many of the abundant fungal orders detected here. Accordingly, both $\mathrm{pH}$ and TPC represent potential axes of variation that may structure some proportion of the differences detected in fungal community composition. We note that our assay of TPC represents a general and nonspecific measure of phenolic and antioxidant compounds 
present in inner bark, preventing us from determining the specific compound classes that may impact fungal community composition (Ainsworth \& Gillespie, 2007). It is critical to note that bark $\mathrm{pH}$, TPC and N appear to be strongly confounded with tree species identity (Figures S7-S9). As a result, we cannot definitively conclude that our measures of bark chemical characteristics drive observed variation among fungal communities without explicit experimental conformation that disentangles these parameters from other host-specific effects. Mechanistic determination of the role of TPC and $\mathrm{pH}$ in environmental filtering sensu stricto (Kraft et al., 2015) would delineate whether fungi colonizing inner bark differentially tolerate the apparently distinct abiotic conditions found across different plant species. These tests, however, are beyond the scope of the current study.

Many of the dominant fungal lineages we detected asymptomatically in inner bark have previously been reported to include a range of endophytic, pathogenic and saprobic lifestyles. For example, the Helotiales and Caetothyriales were both abundant fungal orders recovered from inner tree bark; these taxonomic groups are known to harbour a diverse range of endophytes inhabiting roots and leaves, as well as a range of plant pathogens and saprotrophs (Tedersoo et al., 2009; Teixeira et al., 2017). For example, the Herpotrichiellaceae (Caetothyriales) and the Dermateaceae (Helotiales) were detected across all hosts in our study; these enigmatic fungi are sometimes detected as root endophytes in a range of environments and plant hosts (Allen, Millar, Berch, \& Berbee, 2003; Chen et al., 2015; Jumpponen, Herrera, Porras-Alfaro, \& Rudgers, 2017; Obase \& Matsuda, 2014). Similarly, the Tricholomataceae, a fungal family enriched in white oak bark, is known to include a range of foliar endophytes as well as potent plant pathogens (Lana et al., 2011). The genus Mycena was also found to be dominant in oak bark; Mycena members are well known as saprotrophic white rot fungi, but can also be detected as endophytes in tree roots (Kernaghan \& Patriquin, 2011). Intriguingly, Mycena has previously been collected on the bark of live tropical trees (Desjardin, Capelari, \& Stevani, 2007), but to the best of our knowledge, this is the first known occurrence of this genus inhabiting surface-sterilized inner bark. Additionally, Therrya (class Leotiomycetes, order Rhytismatales) was found in very high abundance in red pine bark ( $41 \%$ of all OTUs); this genus has previously been reported as associated with the bark and stems of pine and other coniferous trees where it occurs as a putative endophyte, as a virulent pathogen (Funk, 1980) or as a saprotroph on standing dead branches (Minter, 1996; Solheim, Torp, \& Hietala, 2013). Together these observations suggest that Therrya may persist with a wider range of lifestyles than previously known. Similarly, Lepteutypa was highly abundant but almost exclusively found in white oak bark; members of this genus are known to form cankers in tree bark, although no discernible cankers were present in any of our sampled bark tissue (Swart, 1973). This may be the first report of this genus growing asymptomatically in inner bark. Finally, white oak bark was enriched in fungi belonging to the Xylariales, a result consistent with previous reports of endophytic Xylaria in oak bark tissue (Collado, Platas, \& Pelaez, 2001; Davis, Franklin, Shaw, \& Vilgalys, 2003; Griffith \& Boddy, 1990).
Xylaria is also frequently reported as a saprotroph and has been postulated to "wait" for plant senescence to opportunistically decay plant tissue, rarely or never conferring a mutualistic benefit to the plant host (Davis et al., 2003).

Observations that identical fungal isolates can be both hypervirulent pathogens or persist as asymptomatic endophytes (Jumpponen et al., 2017; Lana et al., 2011; Sakalidis, Hardy, \& Burgess, 2011) depending upon plant host conditions or coevolutionary history (Lofgren et al., 2018) support the proposition that fungi isolated living endophytically in plant tissue can undergo lifestyle switching (Carroll, 1988; Selosse et al., 2018). Our work significantly expands current understanding of the identity and ecology of fungi inhabiting inner bark and contributes to the evolving interpretation of fungal niches, showing that potentially saprobic or pathogenic fungi may persist asymptomatically in inner bark tissue.

Although our study did not attempt to isolate fungal mycelium, we postulate that a significant proportion of the fungal taxa studied here may be actively growing as hyphae. While it is possible for the physical attributes of different tree species' bark to differentially entrap fungal spores or other dormant fungal life stages, thereby driving the strong differences in fungal communities detected among tree species, there are multiple reasons to suggest that this is unlikely and that bark does not solely act as a passive sieve for fungi. Spores are an especially durable and resistant fungal life history stage (Bruns et al., 2009), making it unlikely that communities of spores or other latent life stages would persist differentially across a range of bark $\mathrm{pH}$ and bark phenolic contents. Reports of actively growing endophytic mycelium, isolated from surface sterilized elm (Webber, 1981), pacific yew (Stierle et al., 1993), beech, oak (Griffith \& Boddy, 1990), pine and larch bark (Kowalski \& Kehr, 1992), indirectly support these claims. Understanding the potential seasonal turnover of these communities will strengthen our understanding of the natural history of these organisms and their role in inner tree bark (Younginger \& Ballhorn, 2017).

We found a mean range of 22-247 fungal OTUs per tree. These results are remarkably consistent with other well-replicated, nextgeneration sequencing studies of fungal endophyte communities. For example, Zimmerman and Vitousek (2012) studied foliar endophytes in a single tree species across a substantial environmental gradient in Hawaii and found a range of 40-257 OTUs per tree. Our methodology probably detected many fungal taxa that are typically isolated with very low frequency when culturing techniques are used (Kowalski \& Kehr, 1992; Hoffman \& Arnold, 2008). Given that diversity estimates generated from molecular sequence data are notoriously coupled with specific sequence processing choices (Dickie, 2010; Nguyen, Smith, Peay, \& Kennedy, 2015; Taylor et al., 2016), we caution against over interpretation of the absolute magnitude of OTU diversity detected here, while maintaining that inner bark fungal communities are reasonably diverse.

Diverse communities of inner bark fungi appear to be ubiquitous across a range of plant taxa and their presence may have ecological implications for our understanding of plant defence and decay dynamics. The potential role of a subset of these fungi in plant 
defence, as has been previously shown for some inner bark fungal endophytes (Alfredsen et al., 2008; Verma et al., 2007; Webber \& Hedger, 1986), remains an intriguing area of research. Future studies exploring the distribution and function of these fungi across plant hosts and geographical locales will assist in our understanding of the dynamics of the growing number of plant diseases that penetrate through tree bark to reach the vascular tissue (Bentz et al., 2010; Herms \& McCullough, 2014; Webber, 1981). Additionally, the unique inner bark fungal assemblages found in each tree species may impact subsequent decay dynamics. The role of inner bark fungi as immediate colonizers of dead plant tissue is plausible (Selosse et al., 2018), especially given the potentially saprotrophic capacity of some of the dominant fungi found here. Distinct fungal assemblages across tree species may drive divergent decay trajectories if they impact the establishment and activity of subsequently arriving wood decay fungi by exerting priority effects (Fukami, 2015). Consistent with this reasoning, wood endophyte communities have been shown to impact the community assembly and function of subsequently arriving saprotrophic fungi by producing a range of bioactive exudates (Cline, Schilling, Menke, Groenhof, \& Kennedy, 2018; Heilmann-Clausen \& Boddy, 2005).

\section{5 | CONCLUSION}

This work highlights that inner tree bark harbours nonrandom fungal assemblages and that these communities are an underappreciated and potentially ubiquitous component of the plant microbiome (Vandenkoornhuyse et al., 2015). By studying the inner bark of different tree species across multiple study sites we provide strong evidence that tree bark of different species and evolutionary histories can serve as an environmental filter structuring fungal community membership. The range of dominant fungal lineages found here include potential plant pathogens and saprotrophs detected asymptomatically as endophytic fungi in inner tree bark; these results support the "dual-niche" flexibility of many endophytic fungi (Selosse et al., 2018). Finally, our study suggests that inner bark fungal communities are comparatively as diverse as some foliar endophyte communities, and the large proportion of unidentified fungal taxa detected in our study may reflect the understudied nature of this plant tissue.

\section{ACKNOWLEDGEMENTS}

Clarisse Betancourt Roman, Rima Upchurch and William Argiroff provided methodological and statistical support. Kayla Mathes assisted with the development of laboratory protocols and Tim James provided valuable discussions and reagents. Four anonymous reviewers provided constructive and detailed feedback. The University of Michigan Integrated Training in Microbial Systems provided funding to P.T.P. DNA sequencing efforts were supported by work performed by The University of Michigan Microbial Systems Molecular Biology Laboratory.

\section{AUTHOR CONTRIBUTIONS}

P.T.P. and D.Z. conceived the experiment and collected samples. P.T.P. wrote the manuscript and analysed the data. P.T.P. and S.O.S. developed the DNA extraction methodology. All authors contributed to the preparation of the final version of the paper.

\section{DATA AVAILABILITY STATEMENT}

Raw sequences and associated metadata have been deposited in SRA. Bioproject: PRJNA546283, samples: SRR9205176-SRR9205. All other metadata are accessible at https://doi.org/10.5061/dryad. k45541j

\section{ORCID}

Peter T. Pellitier iD https://orcid.org/0000-0002-0226-0784

\section{REFERENCES}

Ainsworth, E. A., \& Gillespie, K. M. (2007). Estimation of total phenolic content and other oxidation substrates in plant tissues using Folin-Ciocalteu reagent. Nature Protocols, 2(4), 875-877. https://doi. org/10.1038/nprot.2007.102

Alfredsen, G., Solheim, H., \& Slimestad, R. (2008). Antifungal effect of bark extracts from some European tree species. European Journal of Forest Research, 127(5), 387-393. https://doi.org/10.1007/ s10342-008-0222-x

Allen, T. R., Millar, T., Berch, S. M., \& Berbee, M. L. (2003). Culturing and direct DNA extraction find different fungi from the same ericoid mycorrhizal roots. New Phytologist, 160(1), 255-272. https://doi. org/10.1046/j.1469-8137.2003.00885.x

Arnold, A. E. (2007). Understanding the diversity of foliar endophytic fungi: Progress, challenges, and frontiers. Fungal Biology Reviews, 21(2-3), 51-66. https://doi.org/10.1016/j.fbr.2007.05.003

Arnold, A. E., Maynard, Z., \& Gilbert, G. S. (2001). Fungal endophytes in dicotyledonous neotropical trees: Patterns of abundance and diversity. Mycological Research, 105(12), 1502-1507. https://doi. org/10.1017/S0953756201004956

Arnold, A. E., Maynard, Z., Gilbert, G. S., Coley, P. D., \& Kursar, T. A. (2000). Are tropical fungal endophytes hyperdiverse? Ecology Letters, 3(4), 267-274. https://doi.org/10.1046/j.1461-0248.2000.00159.x

Arnold, A. E., Mejía, L. C., Kyllo, D., Rojas, E. I., Maynard, Z., Robbins, N., \& Herre, E. A. (2003). Fungal endophytes limit pathogen damage in a tropical tree. Proceedings of the National Academy of Sciences of the United States of America, 100(26), 15649-15654. https://doi. org/10.1073/pnas.2533483100

Bálint, M., Bartha, L., O'Hara, R. B., Olson, M. S., Otte, J., Pfenninger, M., ... Schmitt, I. (2015). Relocation, high-latitude warming and host genetic identity shape the foliar fungal microbiome of poplars. Molecular Ecology, 24(1), 235-248. https://doi.org/10.1111/ mec.13018

Bentz, B. J., Régnière, J., Fettig, C. J., Hansen, E. M., Hayes, J. L., Hicke, J. A., ... Seybold, S. J. (2010). Climate change and bark beetles of the western United States and Canada: Direct and indirect effects. BioScience, 60(8), 602-613. https://doi.org/10.1525/ bio.2010.60.8.6

Bruns, T. D., Peay, K. G., Boynton, P. J., Grubisha, L. C., Hynson, N. A., Nguyen, N. H., \& Rosenstock, N. P. (2009). Inoculum potential of 
Rhizopogon spores increases with time over the first $4 \mathrm{yr}$ of a $99-\mathrm{yr}$ spore burial experiment. New Phytologist, 181(2), 463-470.

Carroll, G. (1988). Fungal endophytes in stems and leaves: From latent pathogen to mutualistic symbiont. Ecology, 69(1), 2-9. https://doi. org/10.2307/1943154

Chen, K. H., Miadlikowska, J., Molnár, K., Arnold, A. E., U'Ren, J. M., Gaya, E., ... Lutzoni, F. (2015). Phylogenetic analyses of eurotiomycetous endophytes reveal their close affinities to Chaetothyriales, Eurotiales, and a new order-Phaeomoniellales. Molecular Phylogenetics and Evolution, 85, 117-130. https://doi.org/10.1016/j. ympev.2015.01.008

Christian, N., Herre, E. A., \& Clay, K. (2019). Foliar endophytic fungi alter patterns of nitrogen uptake and distribution in Theobroma cacao. New Phytologist, 222(3), 1573-1583.

Cline, L. C., Schilling, J. S., Menke, J., Groenhof, E., \& Kennedy, P. G. (2018). Ecological and functional effects of fungal endophytes on wood decomposition. Functional Ecology, 32(1), 181-191.

Coleman-Derr, D., Desgarennes, D., Fonseca-Garcia, C., Gross, S., Clingenpeel, S., Woyke, T., ... Tringe, S. G. (2016). Plant compartment and biogeography affect microbiome composition in cultivated and native Agave species. New Phytologist, 209(2), 798-811.

Collado, J., Platas, G., \& Pelaez, F. (2001). Identification of an endophytic Nodulisporium sp. from Quercus ilex in central Spain as the anamorph of Biscogniauxia mediterranea by rDNA sequence analysis and effect of different ecological factors on distribution of the fungus. Mycologia, 93, 875-886.

Cuellar-Gempeler, C., \& Leibold, M. A. (2019). Key colonist pools and habitat filters mediate the composition of fiddler crab-associated bacterial communities. Ecology, 100(4), e02628.

Davis, E. C., Franklin, J. B., Shaw, A. J., \& Vilgalys, R. (2003). Endophytic Xylaria (Xylariaceae) among liverworts and angiosperms: Phylogenetics, distribution, and symbiosis. American Journal of Botany, 90(11), 1661-1667.

Desjardin, D. E., Capelari, M., \& Stevani, C. (2007). Bioluminescent Mycena species from São Paulo, Brazil. Mycologia, 99(2), 317-331.

Dickie, I. A. (2010). Insidious effects of sequencing errors on perceived diversity in molecular surveys. New Phytologist, 188(4), 916-918. https://doi.org/10.1111/j.1469-8137.2010.03473.x

Edgar, R. C. (2013). UPARSE: Highly accurate OTU sequences from microbial amplicon reads. Nature Methods, 10(10), 996-998. https://doi. org/10.1038/nmeth.2604

Evert, R. F. (2006). Esau's plant anatomy: Meristems, cells, and tissues of the plant body: their structure, function, and development. Chichester, UK: John Wiley \& Sons.

Fukami, T. (2015). Historical contingency in community assembly: Integrating niches, species pools, and priority effects. Annual Review of Ecology, Evolution, and Systematics, 46, 1-23. https://doi. org/10.1146/annurev-ecolsys-110411-160340

Funk, A. (1980). New Therrya species parasitic on western conifers. Canadian Journal of Botany, 58(11), 1291-1294.

Glynou, K., Thines, M., \& Maciá-Vicente, J. G. (2018). Host species identity in annual Brassicaceae has a limited effect on the assembly of root-endophytic fungal communities. Plant Ecology \& Diversity., 11, 1-12. https://doi.org/10.1080/17550874.2018.1504332

Griffith, G. S., \& Boddy, L. (1990). Fungal decomposition of attached angiosperm twigs I. Decay community development in ash, beech and oak. New Phytologist, 116(3), 407-415. https://doi. org/10.1111/j.1469-8137.1990.tb00526.x

Hardoim, P. R., Van Overbeek, L. S., Berg, G., Pirttilä, A. M., Compant, S., Campisano, A., ... Sessitsch, A. (2015). The hidden world within plants: Ecological and evolutionary considerations for defining functioning of microbial endophytes. Microbiology Molecular Biology Review, 79(3), 293-320. https://doi.org/10.1128/ MMBR.00050-14
Heilmann-Clausen, J., \& Boddy, L. (2005). Inhibition and stimulation effects in communities of wood decay fungi: Exudates from colonized wood influence growth by other species. Microbial Ecology, 49(3), 399-406. https://doi.org/10.1007/s00248-004-0240-2

Herms, D. A., \& McCullough, D. G. (2014). Emerald ash borer invasion of North America: History, biology, ecology, impacts, and management. Annual Review of Entomology, 59, 13-30. https://doi.org/10.1146/ annurev-ento-011613-162051

Higgins, K. L., Arnold, A. E., Miadlikowska, J., Sarvate, S. D., \& Lutzoni, F. (2007). Phylogenetic relationships, host affinity, and geographic structure of boreal and arctic endophytes from three major plant lineages. Molecular Phylogenetics and Evolution, 42(2), 543-555.

Hoffman, M. T., \& Arnold, A. E. (2008). Geographic locality and host identity shape fungal endophyte communities in cupressaceous trees. Mycological Research, 112(3), 331-344. https://doi.org/10.1016/j. mycres.2007.10.014

Jumpponen, A., Herrera, J., Porras-Alfaro, A., \& Rudgers, J. (2017). Biogeography of root-associated fungal endophytes. In L. Tedersoo (Ed), Biogeography of mycorrhizal symbiosis (pp. 195-222). Berlin, Germany: Springer.

Kernaghan, G., \& Patriquin, G. (2011). Host associations between fungal root endophytes and boreal trees. Microbial Ecology, 62(2), 460-473. https://doi.org/10.1007/s00248-011-9851-6

Kõljalg, U., Nilsson, R. H., Abarenkov, K., Tedersoo, L., Taylor, A. F. S., Bahram, M., ... Larsson, K.-H. (2013). Towards a unified paradigm for sequence-based identification of fungi. Molecular Ecology, 22(21), 5271-5277. https://doi.org/10.1111/mec.12481

Kowalski, T., \& Kehr, R. D. (1992). Endophytic fungal colonization of branch bases in several forest tree species. Sydowia, 44(2), 137-168.

Kraft, N. J., Adler, P. B., Godoy, O., James, E. C., Fuller, S., \& Levine, J. M. (2015). Community assembly, coexistence and the environmental filtering metaphor. Functional Ecology, 29(5), 592-599. https://doi. org/10.1111/1365-2435.12345

Kusari, S., Hertweck, C., \& Spiteller, M. (2012). Chemical ecology of endophytic fungi: Origins of secondary metabolites. Chemistry \& Biology, 19(7), 792-798. https://doi.org/10.1016/j.chembiol.2012.06.004

Lana, T. G., Azevedo, J. L., Pomella, A. W., Monteiro, R. T., Silva, C. B., \& Araújo, W. L. (2011). Endophytic and pathogenic isolates of the cacao fungal pathogen Moniliophthora perniciosa (Tricholomataceae) are indistinguishable based on genetic and physiological analysis. Genetics and Molecular Research, 10(1), 326-334. https://doi.org/10.4238/ vol10-1gmr895

Langrell, S. R. (2005). Development of a nested PCR detection procedure for Nectria fuckeliana direct from Norway spruce bark extracts. FEMS Microbiology Letters, 242(1), 185-193.

Legendre, P., \& Gallagher, E. D. (2001). Ecologically meaningful transformations for ordination of species data. Oecologia, 129(2), 271-280. https://doi.org/10.1007/s004420100716

Legendre, P., \& Legendre, L. F. (2012). Numerical ecology (vol. 24). Amsterdam, the Netherlands: Elsevier.

Lofgren, L. A., LeBlanc, N. R., Certano, A. K., Nachtigall, J., LaBine, K. M., Riddle, J., ... Kistler, H. C. (2018). Fusarium graminearum: Pathogen or endophyte of North American grasses? New Phytologist, 217(3), 1203-1212.

Lücking, R., Hodkinson, B. P., \& Leavitt, S. D. (2017). The 2016 classification of lichenized fungi in the Ascomycota and BasidiomycotaApproaching one thousand genera. The Bryologist, 119(4), 361-417.

McDonald, D., Clemente, J. C., Kuczynski, J., Rideout, J. R., Stombaugh, J., Wendel, D., ... Caporaso, J. G. (2012). The Biological Observation Matrix (BIOM) format or: How I learned to stop worrying and love the ome-ome. GigaScience, 1(1), 7. https://doi.org/10.1186/2047-217X-1-7 Minter, D. W. (1996). Therrya fuckelii. Mycopathologia, 136(3), 171-173.

Nguyen, N. H., Smith, D., Peay, K., \& Kennedy, P. (2015). Parsing ecological signal from noise in next generation amplicon sequencing. 
New Phytologist, 205(4), 1389-1393. https://doi.org/10.1111/ nph.12923

Obase, K., \& Matsuda, Y. (2014). Culturable fungal endophytes in roots of Enkianthus campanulatus (Ericaceae). Mycorrhiza, 24(8), 635-644. https://doi.org/10.1007/s00572-014-0584-5

Oksanen, J., Blanchet, F., Kindt, R., Legendre, P., O'hara, R. B., Simpson, G., Solymos, P., ... Wagner, H. (2011). Multivariate analysis of ecological communities. Vegan Tutorial, 1-40.

Paliy, O., \& Shankar, V. (2016). Application of multivariate statistical techniques in microbial ecology. Molecular Ecology, 25(5), 1032-1057. https://doi.org/10.1111/mec.13536

Petrini, O., \& Fisher, P. J. (1990). Occurrence of fungal endophytes in twigs of Salix fragilis and Quercus robur. Mycological Research, 94(8), 1077-1080.

Porras-Alfaro, A., \& Bayman, P. (2011). Hidden fungi, emergent properties: Endophytes and microbiomes. Annual Review of Phytopathology, 49, 291-315. https://doi.org/10.1146/annurev-phyto-080508-081831

R Core Team (2019). R: A language and environment for statistical computing. Vienna, Austria: R Foundation for Statistical Computing.

Rodriguez, R. J., White, J. F. Jr, Arnold, A. E., \& Redman, R. S. (2009). Fungal endophytes: Diversity and functional roles. New Phytologist, 182(2), 314-330. https://doi.org/10.1111/j.1469-8137.2009.02773.x

Sakalidis, M. L., Hardy, G. E. S., \& Burgess, T. I. (2011). Endophytes as potential pathogens of the baobab species Adansonia gregorii: A focus on the Botryosphaeriaceae. Fungal Ecology, 4(1), 1-14. https://doi. org/10.1016/j.funeco.2010.06.001

Schulz, B., \& Boyle, C. (2005). The endophytic continuum. Mycological Research, 109(6), 661-686. https://doi.org/10.1017/S095375620 $500273 X$

Selosse, M. A., Schneider-Maunoury, L., \& Martos, F. (2018). Time to re-think fungal ecology? Fungal ecological niches are often prejudged. New Phytologist, 217(3), 968-972. https://doi.org/10.1111/ nph.14983

Solheim, H., Torp, T. B., \& Hietala, A. M. (2013). Characterization of the ascomycetes Therrya fuckelii and T. pini fruiting on Scots pine branches in Nordic countries. Mycological Progress, 12(1), 37-44. https://doi.org/10.1007/s11557-012-0813-2

Srivastava, L. M. (1964). Anatomy, chemistry, and physiology of bark. In J. A. Romberger \& P. Mikola (Eds.), International review of forestry research (vol. 1; pp. 203-277). Amsterdam, the Netherlands: Elsevier.

Stierle, A., Strobel, G., \& Stierle, D. (1993). Taxol and taxane production by Taxomyces andreanae, an endophytic fungus of Pacific yew. Science, 260(5105), 214-216. https://doi.org/10.1126/science.8097061

Strobel, G., \& Daisy, B. (2003). Bioprospecting for microbial endophytes and their natural products. Microbiology Molecular Biology Review, 67(4), 491-502. https://doi.org/10.1128/MMBR.67.4.491-502.2003

Swart, H. J. (1973). The fungus causing Cypress canker. Transactions of the British Mycological Society, 61(1), 71-82. https://doi.org/10.1016/ S0007-1536(73)80089-0

Taylor, D. L., Walters, W. A., Lennon, N. J., Bochicchio, J., Krohn, A., Caporaso, J. G., \& Pennanen, T. (2016). Accurate estimation of fungal diversity and abundance through improved lineage-specific primers optimized for Illumina amplicon sequencing. Applied and Environmental Microbiology, 82(24), 7217-7226. https://doi. org/10.1128/AEM.02576-16

Tedersoo, L., Pärtel, K., Jairus, T., Gates, G., Põldmaa, K., \& Tamm, H. (2009). Ascomycetes associated with ectomycorrhizas: Molecular diversity and ecology with particular reference to the Helotiales. Environmental Microbiology, 11(12), 3166-3178.
Teixeira, M. M., Moreno, L. F., Stielow, B. J., Muszewska, A., Hainaut, M., Gonzaga, L., ... de Hoog, G. S. (2017). Exploring the genomic diversity of black yeasts and relatives (Chaetothyriales, Ascomycota). Studies in Mycology, 86, 1-28. https://doi.org/10.1016/j.simyco.2017.01.001

U'Ren, J. M., \& Arnold, A. E. (2016). Diversity, taxonomic composition, and functional aspects of fungal communities in living, senesced, and fallen leaves at five sites across North America. PeerJ, 4, e2768. https://doi.org/10.7717/peerj.2768

Vandenkoornhuyse, P., Quaiser, A., Duhamel, M., Le Van, A., \& Dufresne, A. (2015). The importance of the microbiome of the plant holobiont. New Phytologist, 206(4), 1196-1206. https://doi.org/10.1111/ nph.13312

Verma, V. C., Gond, S. K., Kumar, A., Kharwar, R. N., \& Strobel, G. (2007). The endophytic mycoflora of bark, leaf, and stem tissues of Azadirachta indica A. Juss (Neem) from Varanasi (India). Microbial Ecology, 54(1), 119-125. https://doi.org/10.1007/s00248-006-9179-9

Wang, Y. I., Naumann, U., Wright, S. T., \& Warton, D. I. (2012). mvabundan $\mathrm{R}$ package for model-based analysis of multivariate abundance data. Methods in Ecology and Evolution, 3(3), 471-474.

Warton, D. I., Foster, S. D., De'ath, G., Stoklosa, J., \& Dunstan, P. K. (2015). Model-based thinking for community ecology. Plant Ecology, 216(5), 669-682. https://doi.org/10.1007/s11258-014-0366-3

Webber, J. F. (1981). A natural biological control of Dutch elm disease. Nature, 292(5822), 449-451. https://doi.org/10.1038/292449a0

Webber, J. F., \& Hedger, J. N. (1986). Comparison of interactions between Ceratocystis ulmi and elm bark saprobes in vitro and in vivo. Transactions of the British Mycological Society, 86(1), 93-101. https:// doi.org/10.1016/S0007-1536(86)80120-6

Younginger, B. S., \& Ballhorn, D. J. (2017). Fungal endophyte communities in the temperate fern Polystichum munitum show early colonization and extensive temporal turnover. American Journal of Botany, 104(8), 1188-1194.

Zak, D. R., Host, G. E., \& Pregitzer, K. S. (1989). Regional variability in nitrogen mineralization, nitrification, and overstory biomass in northern Lower Michigan. Canadian Journal of Forest Research, 19(12), 1521-1526. https://doi.org/10.1139/x89-231

Zhou, X., Zhu, H., Liu, L., Lin, J., \& Tang, K. (2010). A review: Recent advances and future prospects of taxol-producing endophytic fungi. Applied Microbiology and Biotechnology, 86(6), 1707-1717. https://doi. org/10.1007/s00253-010-2546-y

Zimmerman, N. B., \& Vitousek, P. M. (2012). Fungal endophyte communities reflect environmental structuring across a Hawaiian landscape. Proceedings of the National Academy of Sciences, 109(32), 1302213027. https://doi.org/10.1073/pnas.1209872109

\section{SUPPORTING INFORMATION}

Additional supporting information may be found online in the Supporting Information section at the end of the article.

How to cite this article: Pellitier PT, Zak DR, Salley SO. Environmental filtering structures fungal endophyte communities in tree bark. Mol Ecol. 2019;28:5188-5198. https://doi.org/10.1111/mec.15237 